\title{
Prolonged small-intestinal transit time in cystic fibrosis
}

\author{
AMBIKA BALI, DAVID E STABLEFORTH, PETER ASQUITH
}

\begin{abstract}
A lactulose hydrogen breath test was performed on 10 patients with cystic fibrosis and 15 control subjects matched for age and sex. All normal subjects had a fasting breath hydrogen concentration of less than 20 ppm. In contrast, seven of the patients with cystic fibrosis had high concentrations (25-170 ppm), which fell to $20 \mathrm{ppm}$ or below on prolonged fasting (14-23 hours). Two patients showed no rise in breath hydrogen concentrations after lactulose, and in one patient the breath hydrogen concentration rose at 15 minutes, suggesting bacterial colonisation of the small bowel. Seven of the patients had prolonged small-bowel transit times (160-390 minutes) compared with those in the control group (50-150 minutes).
\end{abstract}

\section{Introduction}

Abnormal breath hydrogen concentrations after ingestion of glucose in patients with bacterial colonisation of the small intestine was first described by Bond and Levitt. ${ }^{1}$ This finding was confirmed by Metz $e t a l^{2}$ and more recently by Rhodes $e t a l$, who used lactulose instead of glucose. ${ }^{3}$ Measurement of breath hydrogen concentrations after ingestion of lactulose may also be used to estimate small-intestinal transit time. ${ }^{45}$ The test is based on the fact that lactulose is not absorbed in the small intestine in man. On reaching the colon it is fermented by bacteria and hydrogen is released, which is then absorbed and exhaled. The rate of production of hydrogen in the colon is accurately reflected by breath hydrogen concentrations, ${ }^{6}$ hydrogen appearing in the breath within about five minutes of lactulose coming into contact with bacteria in the gut. ${ }^{4}$

We performed the hydrogen breath test in patients with cystic fibrosis to detect possible bacterial colonisation of the small intestine. This may occur in cystic fibrosis because infected sputum is continually produced and swallowed. If present this may contribute to the persistent steatorrhoea noted in patients with.cystic fibrosis despite treatment with pancreatic enzymes and cimetidine. ${ }^{7}$

\section{Subjects and methods}

We studied 10 patients with cystic fibrosis (seven men, three women, aged 17-24). Cystic fibrosis had been diagnosed on the basis of the history, clinical examination, and raised sweat chloride concentrations. All patients had a history of recurrent chest infections and production of sputum. Respiratory symptoms were stable at the time of the test. In addition we studied a control group, which comprised 15 healthy volunteers (nine men and six women, who were medical and nursing staff, aged 18-26).

The breath hydrogen concentration was measured with a Hoek Loos hydrogen breath test unit (Hoogstraat Medische Techniek, Holland). ${ }^{8}$

\footnotetext{
Alastair Frazer and John Squire Metabolic and Clinical Investigation Unit, East Birmingham Hospital, Birmingham B9 5ST AMBIKA BALI, MB, MRCP, research registrar

PETER ASQUITH, MD, FRCP, consultant physician and gastroenterologist Department of Respiratory Medicine, East Birmingham Hospital DAVID E STABLEFORTH, MB, FRCP, consultant physician

Correspondence and reprint requests to: $\mathrm{Dr} P$ Asquith.
}

All antibiotics had been stopped at least two weeks before the test. The subjects were asked to fast from $9 \mathrm{pm}$ the previous day, and breath hydrogen concentration was recorded at $9 \mathrm{am}$. If the concentration was greater than $20 \mathrm{ppm}$ the fast was continued and the concentration recorded until it fell below $20 \mathrm{ppm}$. Lactulose $10 \mathrm{~g}(20 \mathrm{ml}$ of $50 \%$ solution) was then given and breath hydrogen concentration recorded every 10 minutes for three hours or longer until a definite rise was measured.

To determine the effect of prolonged fasting on the hydrogen breath test we studied four controls on two separate occasions, after a 12 hour fast and then after a 24 hour fast. To ascertain the reproducibility of the test when the Hoek Loos breath test unit was used we studied four other controls after a 12 hour fast on two separate occasions.

\section{Results}

Controls-The fasting breath hydrogen concentration in all 15 controls was less than $20 \mathrm{ppm}$. The time taken for the concentration to show a sustained rise above $30 \mathrm{ppm}$ was considered to represent the small-bowel transit time and ranged from 50 to 150 (mean 80) minutes. Prolonged fasting by four subjects did not result in a significant change in small-bowel transit time (case 1,80 and 85 minutes; case 2, 95 and 85 minutes; case 3,85 and 80 minutes; and case 4,100 and 90 minutes). When the test was repeated in four controls the results were not significantly different from those obtained on the first occasion.

Patients with cystic fibrosis-The fasting breath hydrogen concentration was between 25 and $170 \mathrm{ppm}$ in seven patients and less than $20 \mathrm{ppm}$ in three; on prolonged fasting (14-23 hours) it fell below

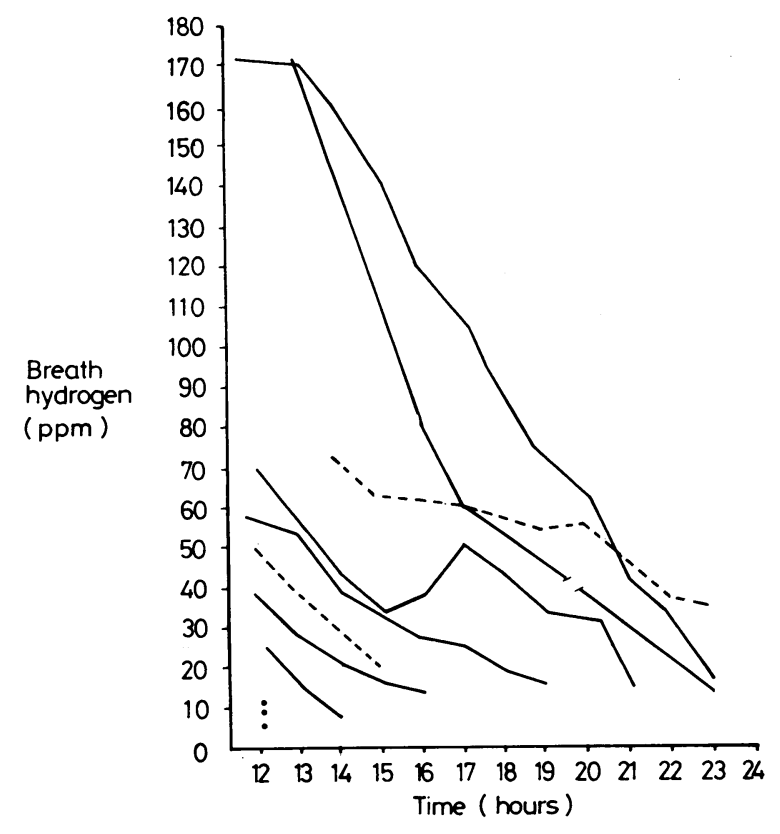

FIG 1 -Fasting breath hydrogen concentrations in 10 patients with cystic fibrosis. Dotted lines indicate concentrations in one patient before (top) and after (bottom) antibiotic treatment.

$20 \mathrm{ppm}$ in six patients (fig 1). In one patient the concentration remained high $(33 \mathrm{ppm})$ after 23 hours of fasting. After ingestion of lactulose it rose to $60 \mathrm{ppm}$ after 15 minutes, with a peak of $96 \mathrm{ppm}$ at 30 minutes. This patient had other evidence of bacterial colonisation of the small intestine (raised urinary indicans, abnormal results on breath testing with ${ }^{14} \mathrm{C}$, and steatorrhoea, which improved after treatment with co-trimoxazole and metronidazole). After antibiotic treatment the 12 hour fasting breath hydrogen concentration was still 
high ( $50 \mathrm{ppm}$ ), but it fell to $19 \mathrm{ppm}$ after 16 hours. The small-intestinal transit time was four hours, which was confirmed by barium meal and follow through examination. In two patients there was no detectable rise in breath hydrogen concentration after ingestion of lactulose; one patient with diabetes mellitus was unable to continue the test after three and a half hours, and the other showed no rise after four hours. The small-bowel transit time was significantly prolonged in seven of the patients (160-390 minutes) compared with the controls (50-150 minutes) (fig $2 ; \mathrm{p}<0.001$, unpaired $t$ test).

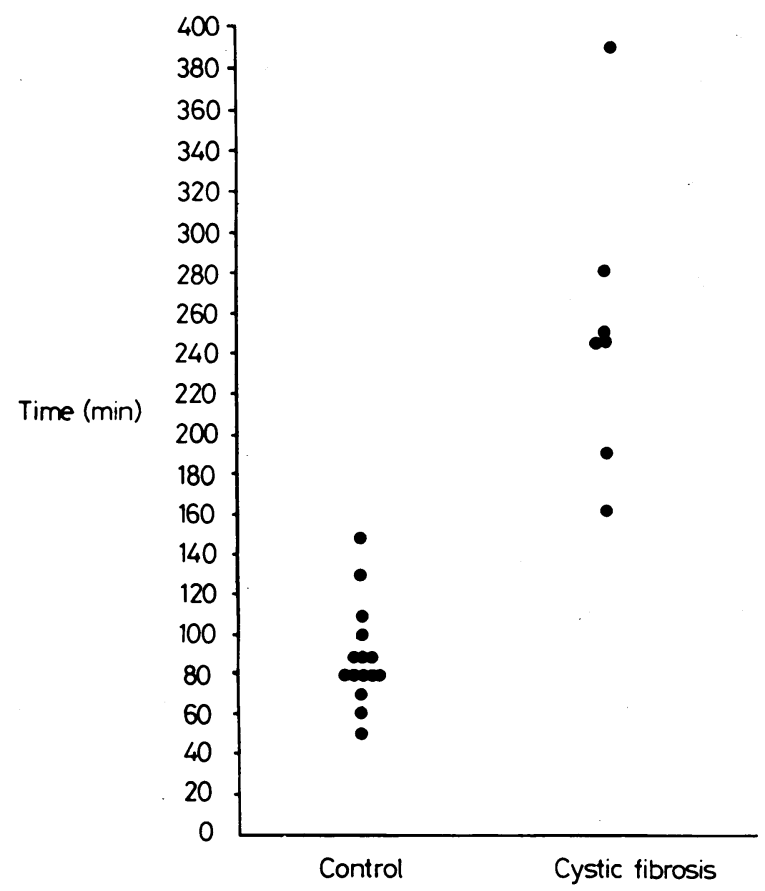

FIG 2-Small-bowel transit time in 15 normal subjects and seven patients with cystic fibrosis.

\section{Discussion}

During the past decade determination of breath hydrogen concentration has become widely used in gastroenterology because it is non-invasive and provides information about a variety of gastroenterological conditions including smallintestinal bacterial overgrowth, ${ }^{2}$ disaccharidase deficiency, ${ }^{9}$ and carbohydrate malabsorption. ${ }^{10}$ It may also be used to measure small-bowel transit time. ${ }^{45}$

Early investigators measured breath hydrogen concentration by gas chromatography using a thermal conductivity detector. ${ }^{16}$ This necessitated expensive equipment which was relatively insensitive to low concentrations of hydrogen. Hence a complicated rebreathing technique was used to collect a concentrated breath sample, the patient being connected to a closed system (for example, a spirometer) for four to five minutes.

The practical application of the test was considerably simplified by the development of a portable gas chromatograph (Hoek Loos breath test unit) in 1978. With this apparatus only a single breath is necessary. The patient exhales deeply via a plastic tube connected to a hole in the unit, and an end expiratory sample is analysed immediately by an electrochemical detector. The unit is compact and may be used at the patient's bedside without the aid of technical staff. In a study ${ }^{8}$ comparing this procedure with the rebreathing method of Bond and Levitt ${ }^{1}$ it was shown that, although the procedure was unsuitable for quantitative determination of excretion of hydrogen, qualitative information was similar and the test was reproducible.

The Hoek Loos breath test unit has several disadvantages. Firstly, it requires an initial warming up time of 45 minutes; secondly, the breath sample has to be made moisture free by silica gel beads, which require repeated dehydration. Thirdly, $\underset{T}{T}$ the scale is in arbitrary units, and the readings have to be plotted on a graph to get the final result in parts per million, and, $\varrho$ finally, in one study the coefficient of variation when duplicate $c$ breath samples were analysed was $17 \%$ with the Hoek Loos $\varrho$ breath test unit and $7 \%$ with the rebreathing method. ${ }^{8}$ Because of these problems newer units (the exhaled $\mathrm{H}_{2}$ monitor, GMI Medical, Renfrew, Scotland, and the exhaled hydrogen monitor, $\infty$ Key Med, Southend-on-Sea) have been developed and are $\varrho$ readily available. With these units the warming up time is minimal, silica gel is not required, the results appear as a digital $\stackrel{\vec{S}}{\rightarrow}$ readout in ppm, and a chart recorder may be used to provide $\overline{0}$ permanent patient records.

The mouth to caecum transit time in normal subjects has been reported as 90-120 minutes, ${ }^{5}$ 25-118 minutes, ${ }^{4}$ and 93 (SEM 6.6) $\stackrel{\mathbb{\Phi}}{\varrho}$ minutes ${ }^{11}$; our results were similar (50-150 minutes).

In a study of patients with diverse gastrointestinal diseases ${ }^{12} \mathrm{\omega}$

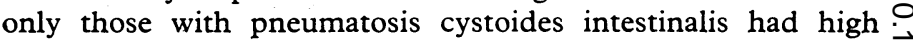
fasting breath hydrogen concentrations. Our patients with $\vec{\omega}$ cystic fibrosis are therefore the second group of patients shown $\stackrel{\circ}{\circ}$ to have high fasting breath hydrogen concentrations, but this is $\frac{0}{3}$ a new finding in cystic fibrosis. High concentrations in cystic i fibrosis might be due to undigested food being present in the $\infty$ colon even after an overnight fast. All the patients in this study of had evidence of pancreatic insufficiency in the form of steator- $\mathscr{E}$ rhoea and azotorrhoea. Carbohydrate digestion in cystic fibrosis is also probably impaired, ${ }^{13}$ and so undigested carbohydrate $\vec{\ominus}$ might reach the colon, where it would be fermented to produce $\overrightarrow{\vec{\rho}}$ hydrogen. The slow intestinal transit would allow undigested 9 food to reach the colon over a prolonged period, and this may $\infty$ contribute to a high fasting breath hydrogen concentration that $\bigcirc$ falls to normal on prolonged fasting. The raised fasting breath $\overrightarrow{0}$ hydrogen concentration noted in pneumatosis cystoides $\frac{\mathbb{D}}{\square}$ intestinalis has been related to intestinal bacteria that produce $\overrightarrow{ }$ hydrogen. ${ }^{12}$ These may also occur in patients with cystic fibrosis, $\oplus$ and it is of note that pneumatosis coli has been reported in $\omega$ cystic fibrosis. ${ }^{14}$ The failure of breath hydrogen concentrations to rise in two patients might be due to absence of lactulose fermenting bacteria in the colon (reported in $2-20 \%$ of a normal population $)^{1015}$ or because the test was not continued for a sufficient length of time.

Small-bowel transit time has not been studied previously in $\vec{F}$ patients with cystic fibrosis, although Weber et al ${ }^{16}$ studied $\frac{\circ}{3}$ mouth to anus transit time in 24 children (aged 2 months to 9 years) with the disease and found it to be rapid (untreated children $13 \cdot 2 \pm 5 \cdot 4$ hours; normal $25 \cdot 4 \pm 7 \cdot 6$ hours). Many other workers have suggested a possible disorder of intestinal motility in cystic fibrosis. ${ }^{717}$ Our results support this hypothesis. Delayed small-intestinal transit in cystic fibrosis might be related to $\frac{0}{3}$ viscid intestinal mucus slowing propulsion of food along the intestine. An intrinsic defect in contraction of intestinal smooth muscle or altered gastrointestinal hormone concentrations in the

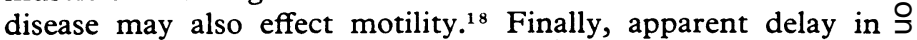
small-bowel transit time might be due to delayed gastric $N$ emptying, but this has not been studied in adults with cystic $D$ fibrosis.

Prolonged small-intestinal transit time in cystic fibrosis could $\bar{N}$ have clinical implications. It might be relevant to the $10 \%$ N incidence of small-intestinal obstruction (meconium ileus $\sigma$ equivalent). ${ }^{19}$ Moreover, intestinal motility is one of the important factors in controlling bacterial colonisation in the intestine, ${ }^{20}{ }^{21}$ and therefore delayed small-bowel transit time in $\stackrel{\mathbb{D}}{\rightarrow}$ cystic fibrosis may encourage bacterial overgrowth of the small bowel (as seen in one of our patients), which in turn might increase malabsorption and further contribute to malnutrition.

We thank the Cystic Fibrosis Research Trust for providing funds for the research; Dr E Elias, who kindly gave permission to use the $\delta$ Hoek Loos breath test unit at the Queen Elizabeth Hospital, Birmingham; Dr J Rhodes for his valuable advice; and Miss Susan Armitage for secretarial help. 


\section{References}

' Bond JH, Levitt MD. Use of pulmonary hydrogen $\left(\mathrm{H}_{2}\right)$ measurements to quantitate carbohydrate absorption. Study of partially gastrectomised patients. F Clin Invest 1972;51:1219-25.

${ }^{2}$ Metz G, Drasar BS, Gassull MA, Jenkins DJA, Blendis LM. Breath hydrogen test for small intestinal bacterial colonisation. Lancet 1976 ; 668-9.

${ }^{3}$ Rhodes JM, Middleton P, Jewell DP. The lactulose $\mathrm{H}_{2}$ breath test as a diagnostic test for small bowel bacterial overgrowth. Scand $\mathcal{f}$ Gastroenterol 1979;14:333-6.

4 Bond JH, Levitt MD. Investigation of small bowel transit time in man utilising pulmonary hydrogen $\left(\mathrm{H}_{2}\right)$ measurements. F Lab Clin Med 1975; 85:546-55

5 Tadesse K, Eastwood MA. Metabolism of dietary fibre components in man assessed by breath $\mathrm{H}_{2}$ and methane. Br F Nutr 1978;40:393-6.

${ }^{6}$ Levitt MD. Production and excretion of hydrogen gas in man. $N$ Engl f Med $1969 ; 281: 122-7$.

7 Boyle BJ, Long WB, Balistrer WF, Widzer SJ, Huang N. Effect of cimetidine and pancreatic enzymes on serum and faecal bile acids and fat absorption in cystic fibrosis. Gastroenterology 1980;78:950-3.

" Dolmans MWV, Hulsberg GT. Breath $\mathrm{H}_{2}$, excretion in carbohydrate malabsorption. Nijmegen, Holland: University of Nijmegen, 1978. MD thesis.

9 Metz G, Jenkins DJA, Newman A, Blendis LM. Breath hydrogen in hyposucrasia. Lancet 1976; ; :119-20.

${ }^{10}$ Bond JH, Levitt HD. Use of breath $\mathrm{H}_{2}$ in the study of carbohydrate absorption. Am F Dig Dis 1977 ;22:379-82.

"Corbett CL, Thomas S, Read NW, Hobson N, Bergman I, Holdsworth CD. Electrochemical detector for breath $\mathrm{H}_{2}$ determination: measure- ment of small bowel transit time in normal subjects and patients with the irritable bowel syndrome. Gut $1981 ; 22: 836-40$.

12 Gillon J, Tadesse K, Logan RFA, Holt S, Sircus W. Breath $\mathrm{H}_{2}$ in pneumatosis cystoides intestinalis. Gut 1979;20:1008-11.

${ }^{13}$ McCollum JPK, Muller DPR, Harries JT. Test meal for assessing intraluminal phase of absorption in childhood. Arch Dis Child 1977;52:887-9.

14 Wood R, Hermann C, Johnson K, di Sant' Agnesse P. Pneumatosis coli in cystic fibrosis. Clinical radiological and pathological features. $A m \mathcal{F} \mathrm{Dis}$ Child 1975;129:246-8.

15 Gilat T, Hur HB, Gelman-Malachi E, Terdiman R, Peled Y. Alterations of colonic flora and their effect on the hydrogen breath test. Gut 1978; 19:602-5.

${ }^{16}$ Weber AM, Roy CC, Morin CL, Lasalle R. Malabsorption of bile acids in children with cystic fibrosis. $N$ Engl $\mathcal{F}$ Med 1973;289:1001-5.

17 Park RW, Grand RJ. Gastrointestinal manifestations of cystic fibrosis. A review. Gastroenterology $1981 ; 81: 1143-61$.

${ }^{18}$ Allen JM, Penketh ARL, Lee YC, Hodson M, Batten C, Bloom SR Elevated plasma neurotensin in adults with cystic fibrosis. Clin $\mathrm{Sci}$ $1983 ; 65: 64$.

${ }^{19}$ Matseshe JW, Go VLW, Di-Magno EP. Meconium ileus equivalent complicating cystic fibrosis in postneonatal children and young adults. Report of 12 cases. Gastroenterology 1977;72:732-6.

${ }^{20}$ Reilly RW, Krisner JB. Blind loop syndrome. Gastroenterology 1959 ;37 : 491.

${ }^{21}$ Dack GM, Petran E. Bacterial activity in different levels of intestine in isolated segments of small and large bowel in monkeys and dogs. $\mathcal{F}$ Infect Dis $1934 ; 54: 204$.

(Accepted 1 fuly 1983)

\title{
Oral iron and the bioavailability of zinc
}

\author{
N J MEADOWS, S L GRAINGER, WARWICK RUSE, P W N KEELING, R P H THOMPSON
}

\section{Abstract}

The oral bioavailability of zinc was studied in nonpregnant adults before and 24 hours after two weeks of oral supplementation with iron and folic acid. Bioavailability was greatly reduced, and the shape of the plasma curves suggested that this was due to impairment of the intestinal absorption of zinc.

The findings suggest that the reduced bioavailability of zinc occurs because of interelement competition in the bowel wall. This might induce zinc depletion.

\section{Introduction}

We have reported that depletion of zinc in maternal tissues is strongly associated with depletion of zinc in fetal tissues and with idiopathic retardation of intrauterine growth. ${ }^{1}$ The mechanisms responsible for maternal depletion are unknown, but in our local population a major cause is probably poor dietary intake, particularly as available zinc is present chiefly in expensive, high protein foods. In addition, dietary metals compete for intestinal absorption, ${ }^{2}$ and therefore routine iron supple-

Gastrointestinal Laboratory, Rayne Institute, St Thomas's Hospital, London SE1 7EH

N J MEADOWS, MB, MRCP, research fellow

S L GRAINGER, MB, MRCP, honorary senior registrar

WARWICK RUSE, MB, MRACP, research fellow

$P$ W KEELING, MD, MRCP, honorary senior registra

R P H THOMPSON, DM, FRCP, consultant physician

Correspondence to: Dr R P H Thompson. ments during pregnancy may decrease the absorption of zinc from the gut. Indeed, Solomons and $\mathrm{Jacob}^{3}$ reported that oral iron given concurrently with zinc to non-pregnant adults results in impaired oral bioavailability (or area under the plasma concentration time curve) of zinc. More prolonged effect of iron, however, has not been assessed.

We have studied the oral bioavailability of zinc given before and after oral supplementation with iron and folic acid.

\section{Patients and methods}

After a 12 hour fast 10 subjects (five men) were given $50 \mathrm{mg}$ elemental zinc (220 $\mathrm{mg}$ zinc sulphate capsules) by mouth. Two baseline $5 \mathrm{ml}$ venous blood samples were taken through a heparinised butterfly cannula before dosing, and then at 30 minute intervals for six hours. The blood was transferred into plastic heparinised tubes, the plasma separated at $400 \mathrm{~g}$ for 20 minutes at $20^{\circ} \mathrm{C}$, and two $1 \mathrm{ml}$ aliquots of plasma-each diluted with $9 \mathrm{ml} 1.0 \mathrm{M} \mathrm{HCl}$-assayed for zinc concentration by atomic absorption spectrophotometry (model IL 257, Instrumentation Laboratories).

Each subject was then given oral iron and folic acid supplements as one Pregaday tablet (ferrous fumarate $(100 \mathrm{mg}$ iron) and folic acid $350 \mu \mathrm{g}$ ) daily for 14 days and zinc bioavailability reassessed 24 hours after the last dose.

In two healthy adults the reproducibility of the areas under the plasma concentration time curves in response to the oral administration of zinc sulphate $(220 \mathrm{mg})$ was studied five times at two week intervals.

The elimination rate constant was calculated by least squares regression analysis of the log plasma zinc concentrations from 30 minutes after the peak until return to the baseline. The time to peak, peak plasma concentration, area under the curve, and elimination rate constant were compared before and after supplementation by two tailed Student's $t$ test.

All patients gave written, informed consent and the study was approved by the hospital's ethical committee. 